“intercultural" and "plurinational" character, which establishes that public policies will integrate diverse cultural practices and knowledge in their configuration, is one of the key issue of the new paradigm.

\section{KEY PIONEERING CONCEPT OF HEALTH, IN THE ECUADORIAN CONSTITUTION}

César Humberto Hermida. Vinculación con la Sociedad, Universidad Central del Ecuador, Quito, Ecuador

10.1136/bmjopen-2015-forum2015abstracts.55

Background The new Ecuadorian Constitution establishes the National Health System of universal coverage free of charge for the users, and the ancestral indigenous concept of "well being" ("Buen vivir" in Spanish, "Sumac Kawsay" in aboriginal Kichwa language). Both political issues require a pioneering paradigm that determines the way health and health services will be handled in the future. The concept of health as satisfaction of human needs, understood as human rights, in the individual objective field (human body), the subjective (cultural) and the social needs (with State responsibilities), seems to be an integrative approach.

Objectives The ancestral concept of healthy collective life, including harmonic relationships between human beings and between human life and nature, is the major purpose of public policies in every field. The Constitution also repossessions public and civil responsibility in the handling of health and health services by establishing a National Health System characterized by Western and aboriginal principles. This should guarantee social equity and a way of life without excessive consumption. A local survey shows the limits of biomedicine and the possibilities of the new concept of health, taking into account the civil society participation.

Methods Once the diagnostic of medical limits is concluded, the concept of optimal physical, mental and social conditions is established, that is to say in the particular (the human body), the singular (cultural) and the social dominions, through bibliographical references and demonstrated in the local field. A case study is developed in two villages at the south of Ecuador, one urban and also a rural indigenous one.

Result Results are showed for the three mentioned dominions, those of the body, nutritional conditions, procreative life, and labour family characteristics, for the cultural or community values as gender, ethnic and generational equity. Also the State general and social services are analysed. Satisfaction of human needs of the body (life styles), the cultural of the group, and the social (quality of life) is demonstrated as valid indicators. That is the concept of "Buen Vivir" in the Spanish version and the "Sumak Kawsay" in the ancestral indigenous version, included in the National Development Ecuadorian Plan.

Conclusion The Ecuadorian experience confirms that equity, efficiency and quality of public services can only be achieved when political determination comes together with strong civil organization and participation The recognition of the Nation's 